\title{
Receptor activator of NF-KB Ligand (RANKL) expression is associated with epithelial to mesenchymal transition in human prostate cancer cells
}

Valerie A Odero-Marah ${ }^{1}$, Ruoxiang Wang ${ }^{1}$, Gina $\mathrm{Chu}^{1}$, Majd Zayzafoon ${ }^{2}$, Jianchun $\mathrm{Xu}^{1}$, Chunmeng Shi ${ }^{1}$, Fray F Marshall ${ }^{1}$, Haiyen E Zhau ${ }^{1}$, Leland WK Chung ${ }^{1}$

${ }^{I}$ Molecular Urology and Therapeutics Program, Department of Urology and Winship Cancer Institute, Emory University School of Medicine, 1365B Clifton Road, NE, Atlanta, GA 30322, USA; ${ }^{2}$ Department of Pathology, University of Alabamn, Birmingham, AL 35294, USA

Epithelial-mesenchymal transition (EMT) in cancer describes the phenotypic and behavioral changes of cancer cells from indolent to virulent forms with increased migratory, invasive and metastatic potential. EMT can be induced by soluble proteins like transforming growth factor $\beta 1$ (TGF $\beta 1$ ) and transcription factors including Snail and Slug. We utilized the $\mathrm{ARCaP}_{\mathrm{E}} / \mathrm{ARCaP}_{\mathrm{M}}$ prostate cancer progression model and $\mathrm{LNCaP}$ clones stably overexpressing Snail to identify novel markers associated with EMT. Compared to $\mathrm{ARCaP}_{\mathrm{E}}$ cells, the highly tumorigenic mesenchymal $\mathrm{ARCaP}_{\mathrm{M}}$ and $\mathrm{ARCaP}_{\mathrm{M} 1}$ variant cells displayed a higher incidence of bone metastasis after intracardiac administration in SCID mice. $\mathrm{ARCaP}_{\mathrm{M}}$ and $\mathrm{ARCaP}_{\mathrm{M} 1}$ expressed mesenchymal stromal markers of vimentin and $\mathrm{N}$-cadherin in addition to elevated levels of Receptor Activator of NF-KB Ligand (RANKL). We observed that both epidermal growth factor (EGF) plus TGFß1 treatment and Snail overexpression induced EMT in $\mathrm{ARCaP}_{\mathrm{E}}$ and $\mathrm{LNCaP}$ cells, and EMT was associated with increased expression of RANKL protein. Finally, we determined that the RANKL protein was functionally active, promoting osteoclastogenesis in vitro. Our results indicate that RANKL is a novel marker for EMT during prostate cancer progression. RANKL may function as a link between EMT, bone turnover, and prostate cancer skeletal metastasis. Keywords: EMT, bone microenvironment, RANKL, prostate cancer, bone metastasis, EGF, TGF $\beta 1$, Snail Cell Research (2008) 18:858-870. doi: 10.1038/cr.2008.84; published online 22 July 2008

\section{Introduction}

EMT in cancer cells is an event reminiscent of the invasion front of migrating cells during embryonic development [1]. A switch from a tightly clustered cobblestone-like appearance to loosely associated spindle-shaped mesenchymal stromal morphology characterizes EMT. This morphologic switch is accompanied by markedly elevated expression of mesenchymal-associated genes, such as vimentin, $\mathrm{N}$-cadherin, and fibronectin, and decreased

Correspondence: Haiyen E Zhau ${ }^{\mathrm{a}}$, Leland WK Chung ${ }^{\mathrm{b}}$

Tel: +1-404-778-4319; Fax: +1-404-778-3675

E-mail: ahzhau@emory.edu; blwchung@emory.edu

Abbreviations: EMT (epithelial-mesenchymal transition); RANKL (receptor activator of NF- $\mathrm{KB}$ ligand); TGF $\beta 1$ (transforming growth factor $\beta 1$ ); EGF (epidermal growth factor); OPG (osteoprotegerin)

Received 11 April 2007; revised 3 March 2008; accepted 7 March 2008; published online 22 July 2008 production of epithelial-specific markers, including E-cadherin and cytokeratins. It has been widely reported that, by undergoing EMT, cancer cells gain increased growth and malignant potential [2-4]. Results obtained from various experimental models revealed that through EMT cancer cells became more migratory, invasive, and metastatic [57]. Although EMT is well studied in vitro, data on EMT occurrence in specific solid tumors in vivo and its relevance to the process of cancer progression have been scarce.

Soluble factors such as epidermal growth factor (EGF), scatter factor/hepatocyte growth factor (SF/HGF), and members of the transforming growth factor, TGF $\beta 1$, and basic fibroblast growth factor (bFGF) families have been shown to promote EMT in several model systems [1, 8 , 9]. The EpH4 mouse mammary epithelial cell line, for example, was promoted to undergo EMT by cooperation of active Ras and TGF $\beta$ via signaling through the MAPK, ERK, and phosphoinositide 3 kinase (PI3K) pathways [10]. Insulin-like growth factor II (IGF-II) stimulated EMT in 
NBT-II rat bladder carcinoma cells via nuclear translocation of $\beta$-catenin [11]. These soluble growth factors, known to be abundant in the bone microenvironment [12], are released upon increased bone turnover and could fuel cancer growth. The Snail transcription factor, a downstream target of TGF $\beta 1$, has been shown to induce EMT in several in vitro cell models for breast, ovarian, and bladder cancers [ 3 , 13-15]. In a human squamous cell carcinoma (SCC) model, EMT was induced by overexpression of Snail and SIP1, or by TGF $\beta 1$ treatment [16]. A common theme seems to be a coordinated suppression of adhesion molecules E-cadherin and desmosomal proteins (desmoplakin, desmoglein), with a concomitant activation of vimentin, fibronectin, and collagens $[1,5,9]$.

EMT is not as well studied in prostate cancer as in other cancers. Prostate cancer cells have been shown to overexpress TGF $\beta 1$, which stimulates angiogenesis and inhibits immune responses, and thus promotes cancer growth [17]. Zhau et al. observed increased invasion and growth of human prostate cancer PC-3 cells following transfection with c-erbB2/neu, coordinated by vimentin overexpression [18]. EMT was also induced in PC-3 cells through transfection with human kallikrein 4 gene [19].

Receptor Activator of NF- $\mathrm{B}$ Ligand (RANKL), a member of the TNF family, is a protein normally expressed on the surface of stromal cells and osteoblasts, and mediates osteoclast differentiation and osteolytic bone resorption [20, 21]. Physiologically, RANKL binds RANK receptor on the surface of the osteoclast, and this interaction can be blocked by osteoprotegerin (OPG), a decoy receptor for RANKL [22]. Although prostate cancer bone metastases are mostly osteoblastic in nature, both osteoblastic and osteolytic lesions can be seen [23,24]. Bone resorption can be shown by an increase in serum and urine markers, demonstrating increased bone turnover during prostate cancer bone metastasis [25]. The 'vicious cycle' theory proposes that increased bone resorption results in elevated TGF $\beta$, which promotes cancer cells to synthesize parathyroid hormone-related peptide (PTHrP) that stimulates RANKL expression by osteoclasts, resulting in osteoclastogenesis [26]. Recently, increased RANKL expression has been detected in human prostate cancers [27, 28], indicating a direct effect of the prostate cancer cells on osteoclastogenesis [27, 29].

We recently reported the establishment of the first human prostate cancer EMT animal model [30]. ARCaP human prostate cancer cells were found to acquire mesenchymal stromal properties following xenograft growth in the host bone. We report here that soluble factors EGF and TGF $\beta 1$, or Snail transcription factor, can also induce EMT in AR$\mathrm{CaP}$ cells, and EMT in LNCaP cells can be induced by Snail overexpression. Upon inducing EMT, elevated expression of functional RANKL was found in both the ARCaP and LNCaP models. Our data suggest a possible link between EMT and elevated RANKL expression and provide supportive rationales for targeting RANKL-mediated signaling in prostate cancer bone metastasis.

\section{Results}

\section{The bone microenvironment promoted EMT and increased} prostate cancer invasion in mice

We previously reported that, based on morphologic and behavioral features, ARCaP human prostate cancer cells could be separated into epithelial-like $\mathrm{ARCaP}_{\mathrm{E}}$ and mesenchymal stromal-like $\mathrm{ARCaP}_{\mathrm{M}}$ subclones, while $\mathrm{ARCaP}_{\mathrm{E}}$ underwent EMT after interaction with both bone and adrenal gland in immune-compromised mice [30]. In the current study, to investigate the mechanism for the transition, $\mathrm{ARCaP}_{\mathrm{E}}$ and $\mathrm{ARCaP}_{\mathrm{M}}$ cells were injected by the intracardiac route into SCID mice for spontaneous bone metastasis.

This series of experiments revealed that $\mathrm{ARCaP}_{\mathrm{M}}$ cells displayed more aggressive bone metastatic capability, with

Table 1 Metastatic potential of ARCaP sublines in the progression model ${ }^{\mathrm{a}}$

\begin{tabular}{|c|c|c|c|}
\hline Cell & Incidence $(\%)$ & Bone metastatic sites & Latency (range in days) \\
\hline $\mathrm{ARCaP}_{\mathrm{E}}$ & $1 / 8(12.5)$ & Femur, tibia & 71 \\
\hline $\mathrm{ARCaP}_{\mathrm{M} 1}^{\mathrm{b}}$ & $11 / 14(78.6)$ & Mandible, femur, tibia, pelvis, rib, sternum, spine & $77.9 \pm 26.4(51-130)^{\mathrm{c}}$ \\
\hline
\end{tabular}


an incidence of $38.9 \%$ compared to $\mathrm{ARCaP}_{\mathrm{E}}$, which had a $12.5 \%$ incidence of tumor formation in the bone (Table 1). We then isolated cancer cells from the $\mathrm{ARCaP}_{\mathrm{M}}$ bone tumors and denoted the isolate as $\mathrm{ARCaP}_{\mathrm{M} 1}$. Cells from $\mathrm{ARCaP}_{\mathrm{Ml}}$, upon another round of intracardiac administration, showed a markedly increased $78.6 \%$ incidence of bone metastasis. Moreover, a significantly shortened latency period was observed for $\mathrm{ARCaP}_{\mathrm{M} 1}$ as compared to $\mathrm{ARCaP}_{\mathrm{M}}$ (Table 1).
We have previously observed a similar effect from the bone microenvironment on $\mathrm{ARCaP}_{\mathrm{E}}$ cells [30]. Cancer cells derived from $\mathrm{ARCaP}_{\mathrm{E}}$ bone tumor exhibited markedly increased tumorigenicity upon a second intracardiac implant. In addition, the cancer cells from $\mathrm{ARCaP}_{\mathrm{E}}$ bone tumor displayed morphologic changes, from the original cobblestone to a spindle-shaped scattered shape in culture, suggestive of the occurrence of EMT. To further investigate the process, we performed a series of histopathological

A
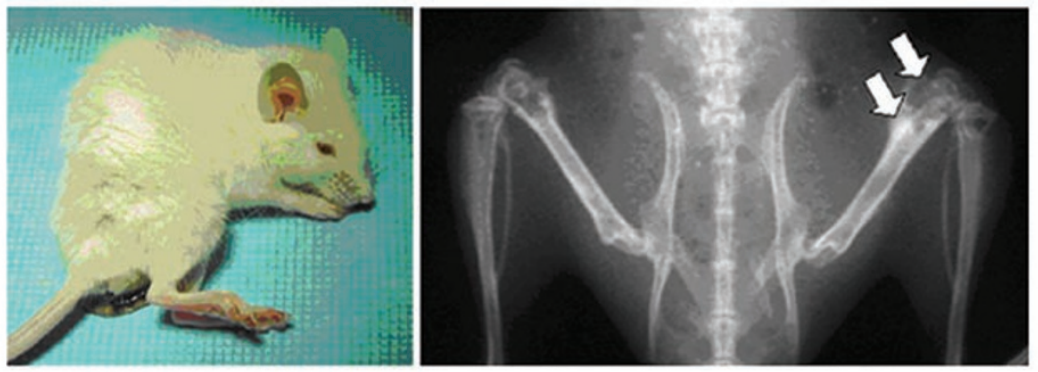

B

Control

Vimentin

Snail

RANKL
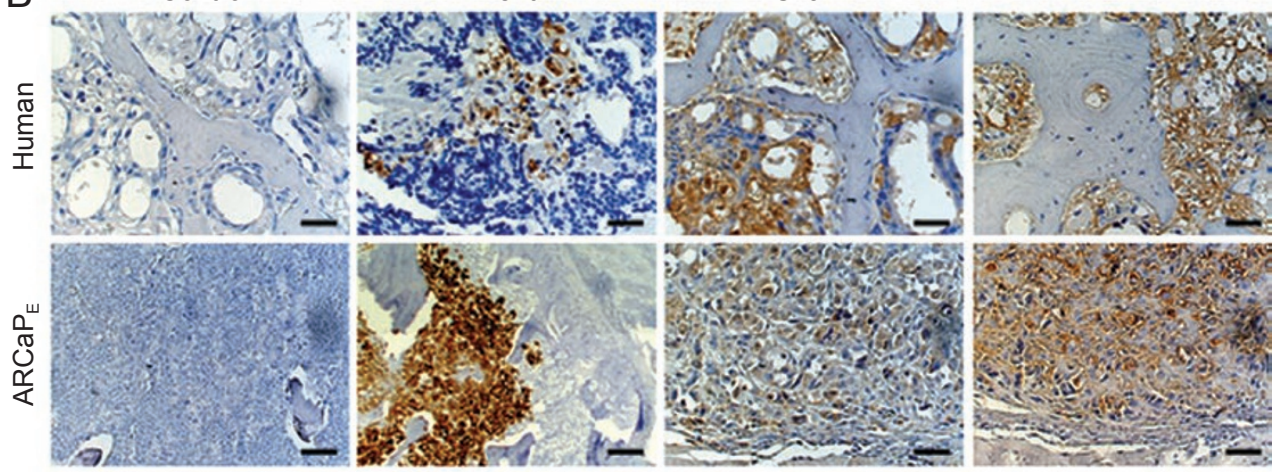

C

Primary tumors
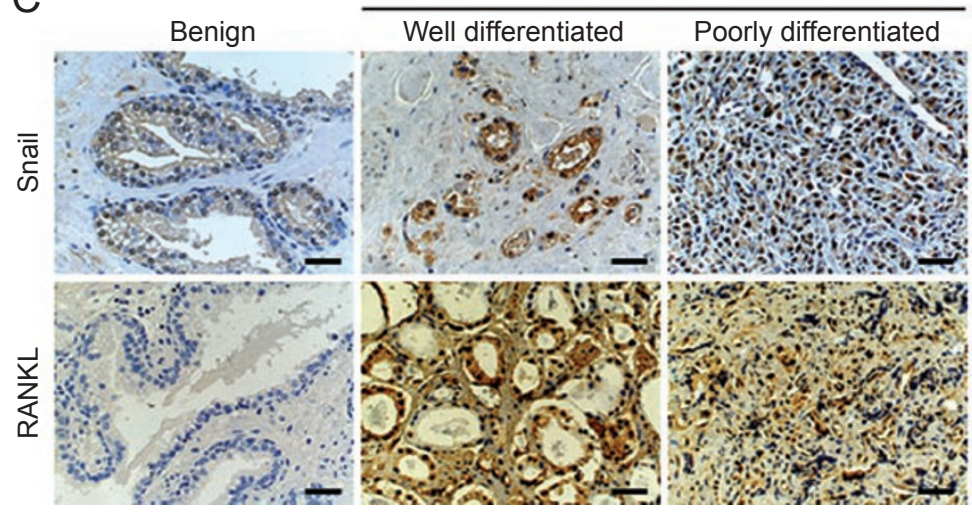

Bone metastasis
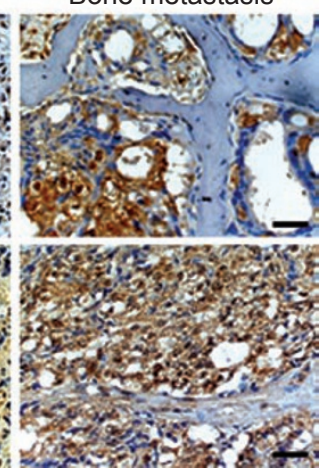

Figure $1 \mathrm{ARCaP}$ subclones exhibited bony metastases. $\mathrm{ARCaP}_{\mathrm{E}}$ and $\mathrm{ARCaP} \mathrm{P}_{\mathrm{M}}$ cells were injected intracardiacally into SCID mice for spontaneous bone tumor formation. (A) A representative mouse developed cachexia and paraplegia during the late stages of $\mathrm{ARCaP}_{\mathrm{E}}$ bone metastasis (left panel). A representative X-ray depicts osteoblastic and osteolytic lesions (arrows) in the mouse femur (right panel). (B) EMT is a general feature in prostate cancer bone metastasis. A human specimen of prostate cancer bone metastasis (upper row, human) and an $\mathrm{ARCaP}_{\mathrm{E}}$ xenograft bone tumor (lower row, $\mathrm{ARCaP}_{\mathrm{E}}$ ) were examined to identify the occurrence of EMT in a parallel immunohistochemical analysis. Bar $=120 \mu \mathrm{m}$. (C) Progressive expression of Snail and RANKL in human prostate cancer specimens. Representative tumor tissue histopathologies are shown. Bar $=120 \mu \mathrm{m}$. 
analyses of $\mathrm{ARCaP}_{\mathrm{E}}$ bone tumor.

Mice bearing the $\mathrm{ARCaP}_{\mathrm{E}}$ bone tumor developed cachexia as shown in the representative picture (Figure 1A, left panel). Under X-ray radiography, regions of bone metastases were seen with mixed osteoblastic/osteolytic lesions (Figure 1A, right panel), and these results were confirmed by $H \& E$ staining of the tumor specimens harvested from mouse bone (data not shown). To confirm that the $\mathrm{ARCaP}_{\mathrm{E}}$ cells in the bone tumor have undergone EMT, we examined the expression of vimentin, which was considered a mesenchymal-specific protein and a typical EMT marker. A collection of human specimens of clinical prostate cancer bone metastasis was stained in parallel with the $\mathrm{ARCaP}_{\mathrm{E}}$ bone tumors. We found increased vimentin staining in both the human specimens and the $\mathrm{ARCaP}_{\mathrm{E}}$ bone tumors, and the stains appeared to be specifically located in the tumor cells (Figure 1B). Using the same strategy, we examined the expression of a panel of genes that were considered to be mesenchymal-specific, and observed that tumor cells transitioning to express mesenchymal markers emerged as a general trend (data not shown).

Interestingly, this series of analysis revealed a coordinated expression of Snail and RANKL upon the occurrence of EMT (Figure 1B). In another examination of these two genes in a series of clinical prostate cancer specimens, both Snail and RANKL were found to be differentially expressed during prostate cancer progression and metastasis (Figure 1C). Snail, as a transcription factor, is known to promote EMT both in developmental processes and in cancer metastasis [31-33]. RANKL is a potent paracrine factor for osteoclastogenesis and bone resorption [34, 35]. Because of the pathophysiological importance of these genes, we performed further investigations to illuminate the regulatory relationship between these genes.

\section{RANKL is a novel EMT marker in the ARCaP human pros- tate cancer progression model}

Since RANKL is known to be an important protein in the colonization of prostate cancer cells in bone [27, 29], we examined whether RANKL is a specific biomarker associated with EMT in the ARCaP progression model. We compared the expression of the conventional EMT markers and RANKL in $\mathrm{ARCaP}_{\mathrm{E}}, \mathrm{ARCaP}_{\mathrm{M}}$, and $\mathrm{ARCaP}_{\mathrm{M} 1}$ cells. Morphologically, $\mathrm{ARCaP}_{\mathrm{E}}$ formed tight cobblestone clusters while $\mathrm{ARCaP}_{\mathrm{M}}$ and its variant, $\mathrm{ARCaP}_{\mathrm{M} 1}$, were more spindle-shaped and scattered in culture (Figure 2A). Western blot analysis showed decreased E-cadherin but increased N-cadherin, vimentin, and RANKL expression in $\mathrm{ARCaP}_{\mathrm{M}}$ and $\mathrm{ARCaP}_{\mathrm{M} 1}$, when compared to $\mathrm{ARCaP}_{\mathrm{E}}$ (Figure 2B). With the exception of vimentin, RT-PCR results corresponded with the Western blot results. Vimentin expression only differed at the protein level, indicative of a

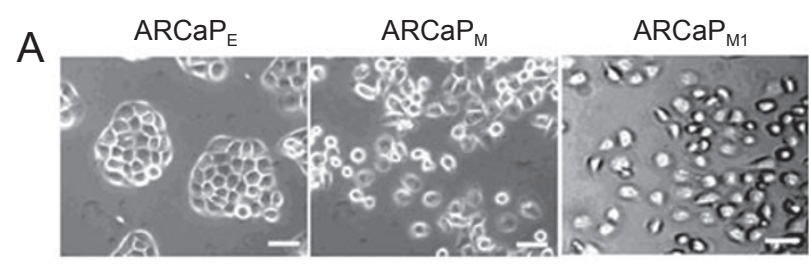

B

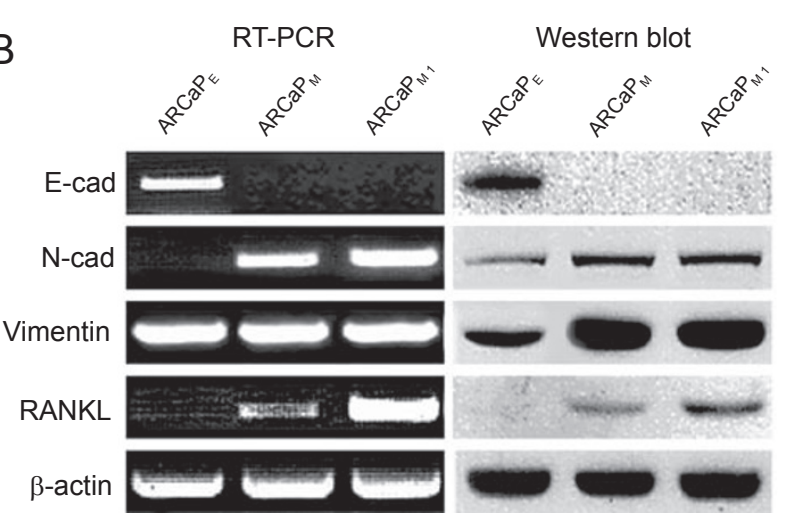

Figure 2 RANKL is a novel EMT marker in the ARCaP EMT model. (A) Phase contrast microscopy revealed cobblestone epithelial clusters for $\mathrm{ARCaP}_{\mathrm{E}}$, while $\mathrm{ARCaP}_{\mathrm{M}}$ and $\mathrm{ARCaP}_{\mathrm{M} 1}$ were more fibroblastic. Bar $=120 \mu \mathrm{m}$. (B) RT-PCR (left panel) and Western blot (right panel) analyses showed decreased E-cadherin (E-cad), and increased $\mathrm{N}$-cadherin ( $\mathrm{N}$-cad), vimentin, and RANKL in the EMT model, from $\mathrm{ARCaP}_{\mathrm{E}}$ to $\mathrm{ARCaP}_{\mathrm{M}}$ and $\mathrm{ARCaP}_{\mathrm{M} 1}$. Levels of the $\beta$-actin were used as loading controls. Note that vimentin expression differences could only be detected at the protein level. Results shown are representative of three independent experiments.

post-transcriptional regulation of this protein. Our results show that the differential expression of RANKL is associated with EMT in the ARCaP prostate cancer progression model.

Both EGF and TGFB1 were required to induce and maintain EMT in ARCaP $P_{E}$ cells

TGF $\beta 1$ and EGF have been shown to induce EMT in many cancer cells [36-38]. Since these soluble factors are known to be available in bone and at primary sites of prostate cancer growth, we tested whether these growth factors could stimulate EMT in the $\mathrm{ARCaP}_{\mathrm{E}}$ cells. We found that treatment with either EGF (50 ng/ml) or TGF $\beta 1(4 \mathrm{ng} / \mathrm{ml})$ for $72 \mathrm{~h}$ was unable to induce morphologic changes in $\mathrm{ARCaP}_{\mathrm{E}}$ cells. A combination of EGF with TGF $\beta 1$, however, led to cell morphologic changes from predominantly cobblestone epithelial shape to spindle fibroblast-like shape (Figure 3A).

We performed immunocytochemical staining to further confirm the occurrence of EMT in the treated $\mathrm{ARCaP}_{\mathrm{E}}$ cells. Following combinatory treatment with EMT and TGF $\beta 1$, $\mathrm{N}$-cadherin expression increased at $48 \mathrm{~h}$, followed by de- 


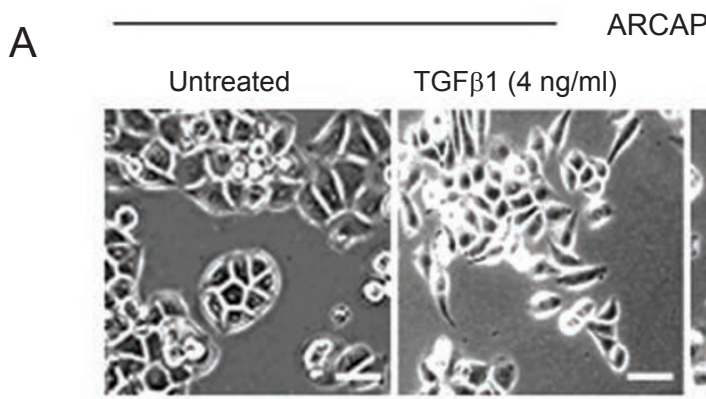

ARCAP $_{E}$

ARCaPM

B
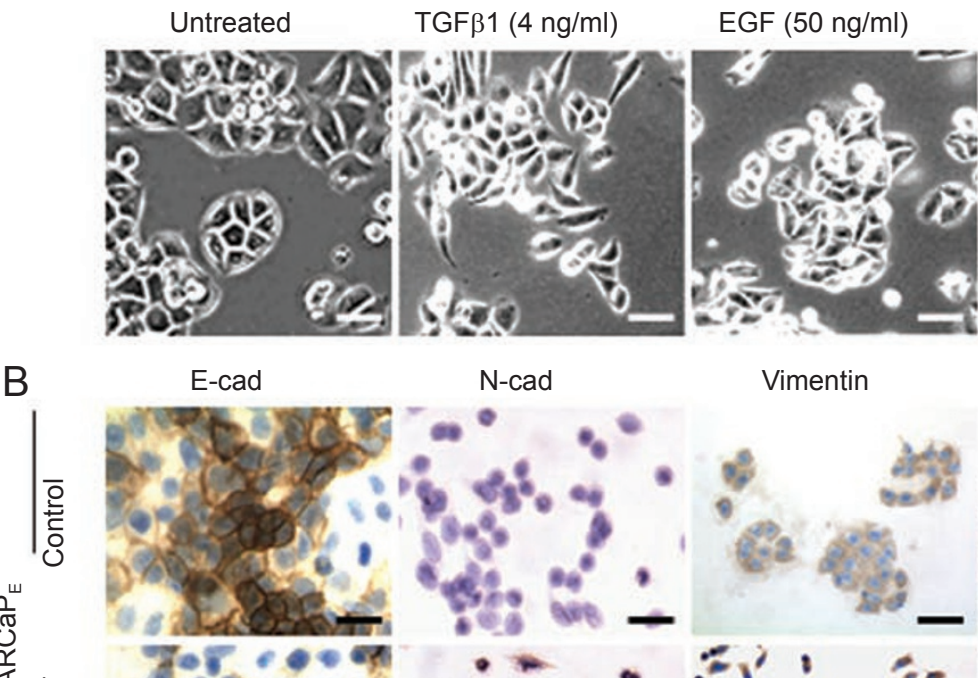

TGF $\beta 1+E G F$

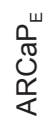
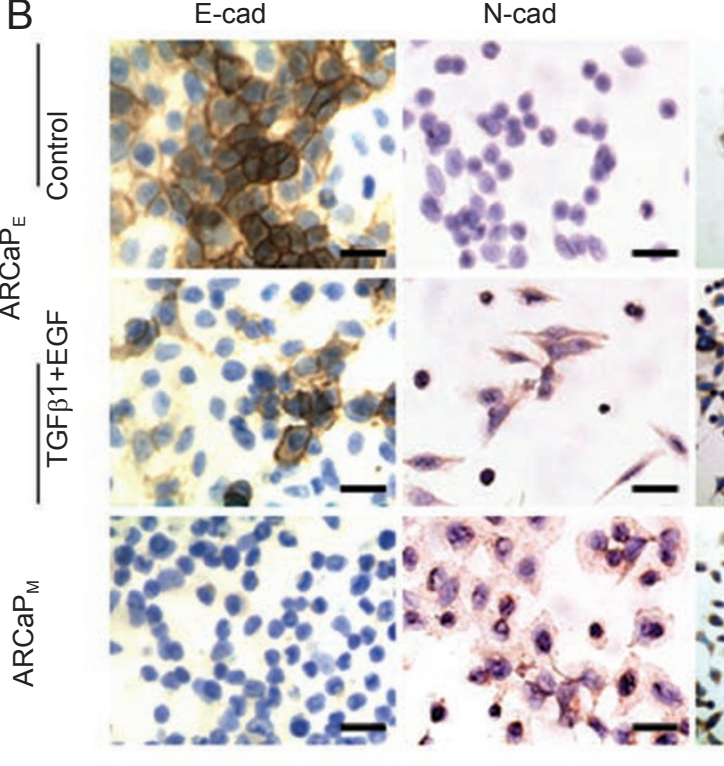

Vimentin
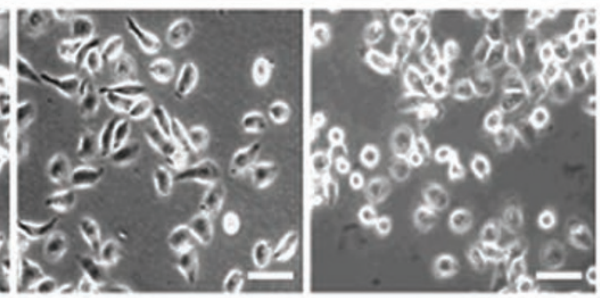

RANKL

Control

C

D

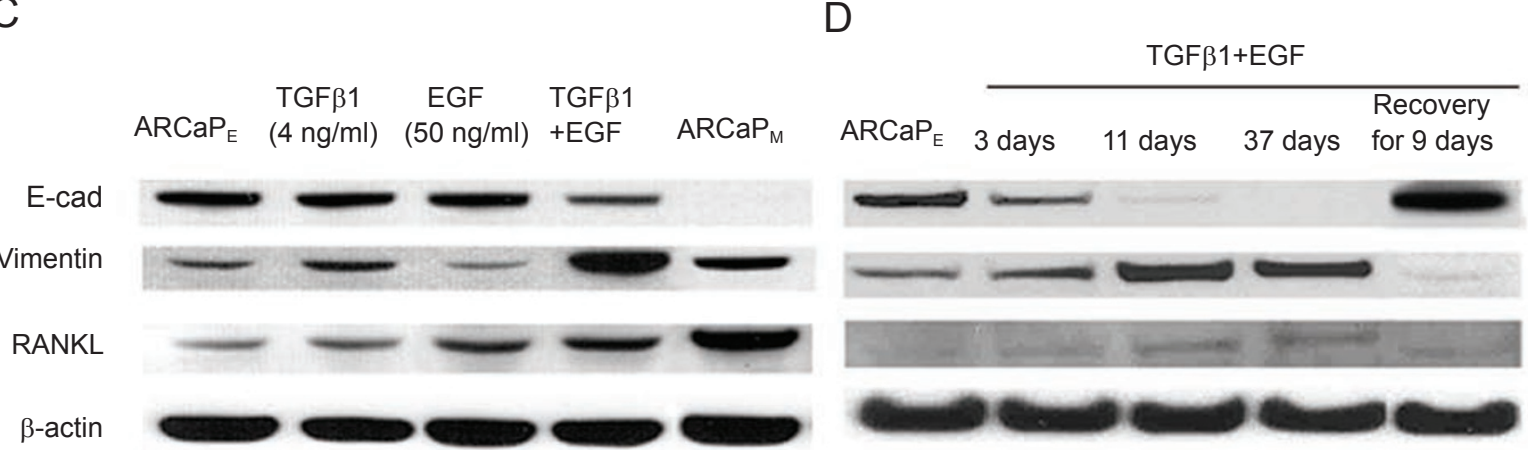

Figure 3 TGF $\beta 1$ plus EGF, but not individual growth factor alone, induced $\mathrm{ARCaP}_{\mathrm{E}}$ to undergo EMT associated with increased RANKL expression. (A) Treatment with both growth factors was required to induce changes in cell morphology from epithelial to spindle shaped. Bar $=120 \mu \mathrm{m}$. (B) EMT marker gene expression was detected by immunocytochemistry. Bar $=120 \mu \mathrm{m}$. $(\mathbf{C})$ EMT-associated protein profiles were confirmed by Western blot analysis, showing decreased E-cad, increased vimentin and RANKL. (D) Western blot analysis of $\mathrm{ARCaP}_{\mathrm{E}}$ cells treated with TGF $\beta 1$ plus EGF $(T+E)$ for 3, 11, 37, or 37 days, followed by withdrawal of growth factors for 9 days. The absence of $(T+E)$ reversed EMT. All blots were stripped and subsequently reprobed for $\beta$-actin as a loading control.

creased E-cadherin and increased vimentin and RANKL expression at $72 \mathrm{~h}$ (Figure 3B). Western blot analysis showed that, while separate treatment with TGF $\beta 1$ or EGF for $72 \mathrm{~h}$ only slightly decreased E-cadherin and increased vimentin and RANKL levels, the combination treatment significantly and additively decreased the expression of E-cadherin and increased the expression of vimentin and RANKL (Figure 3C). 
Long-term treatment with $4 \mathrm{ng} / \mathrm{ml} \mathrm{TGF} \beta 1$ plus $50 \mathrm{ng} / \mathrm{ml}$ EGF $(T+E)$ for up to 37 days supported the EMT transition of $\mathrm{ARCaP}_{\mathrm{E}}$ cells, as illustrated by decreased E-cadherin and increased vimentin protein expression (Figure 3D). This growth factor-mediated EMT was associated with increased RANKL protein expression. Upon growth factor withdrawal for 9 days following the 37-day treatment $[37 d(T+E), 9 d(-)]$, the EMT was reversed, as shown by
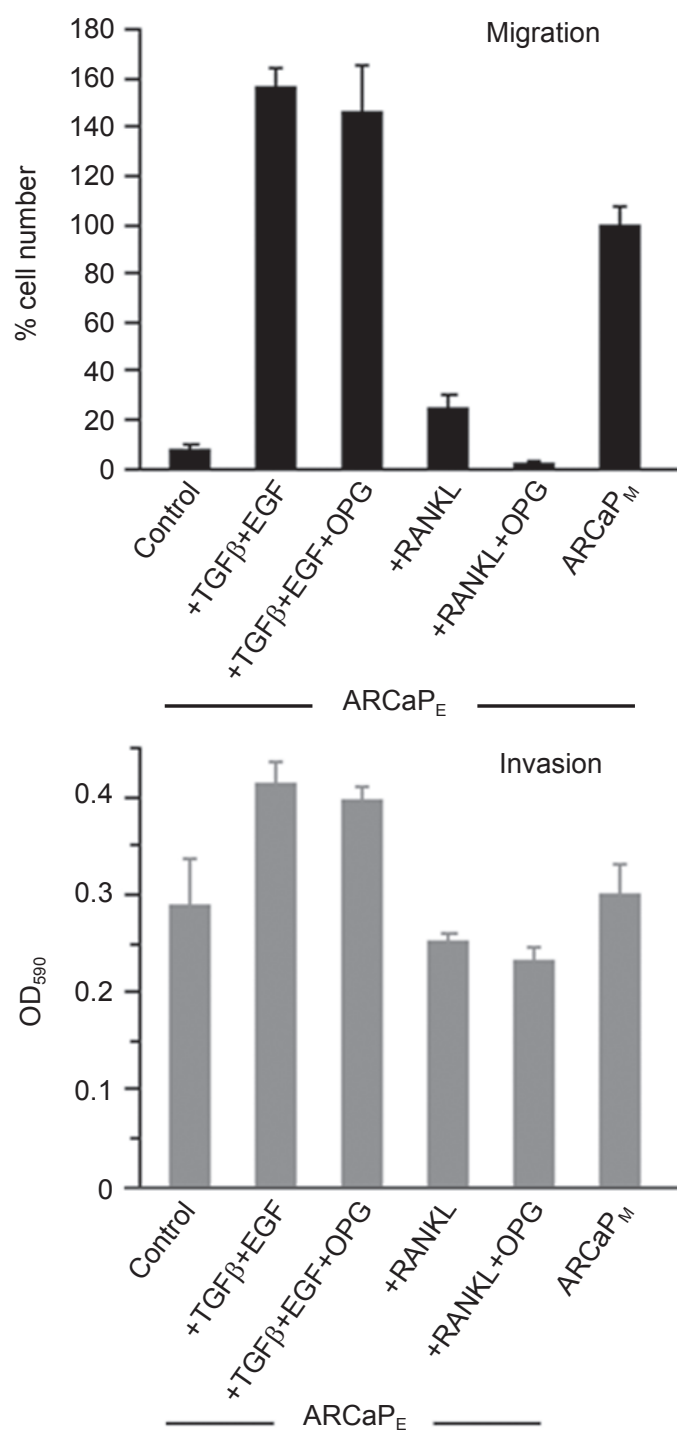

Figure 4 Increased migration and invasion are associated with EMT promoted by growth factor treatment of $\mathrm{ARCaP}_{\mathrm{E}}$ cells. Growth factor-treated cells that had migrated across collagen matrix were counted to determine the percentage cell migration relative to AR$\mathrm{CaP}_{\mathrm{M}}$ as a positive control (top panel). Cells that invaded through matrigel matrix were fixed, stained, solubilized, and OD590 nm read to obtain relative invasion (bottom panel). Data represent the average \pm standard deviation from four separate experiments with 2-3 replicates per experiment. a switch of gene expression profiles toward that of the original $\mathrm{ARCaP}_{\mathrm{E}}$ cells (Figure 3D). In a separate study addressing the effect of Snail on $\mathrm{ARCaP}_{\mathrm{E}}$ cells [39], we also observed increased expression of Snail, a transcription factor that can induce EMT, in $\mathrm{ARCaP}_{\mathrm{E}}$ cells treated with TGF $\beta 1$ and EGF, most significantly after 11 and 37 days. These results support the hypothesis that the growth factor milieu is required to maintain the EMT phenotype, possibly through up-regulation of Snail transcription factor. In addition, co-treatment of $\mathrm{ARCaP}_{\mathrm{E}}$ cells with the RANK decoy receptor, OPG $(50 \mathrm{ng} / \mathrm{ml})$, did not block expression of EMT markers induced by TGF $\beta 1$ and EGF, nor did it inhibit RANKL expression, suggesting that the inhibition of RANK binding to RANKL does not affect EMT (data not shown). Similarly, treatment of ARCaP $_{M}$ with $50 \mathrm{ng} / \mathrm{ml}$ OPG did not abolish EMT; vimentin and RANKL expression and levels of E-cadherin expression were not changed in these studies (data not shown). Therefore, both TGF $\beta 1$ and EGF are required to induce and maintain EMT in the human prostate cancer ARCaP cell model, while blocking RANKL-RANK interaction using OPG does not abolish EMT.

EMT induced by TGFB1 plus EGF is accompanied by increased migration and invasion of ARCaP cells

We assessed ARCaP cell behavioral changes after growth factor-induced EMT. Cell migration in the Boyden chambers increased approximately 15 -fold after treatment of $\mathrm{ARCaP}_{\mathrm{E}}$ with both TGF $\beta 1$ and EGF for $48 \mathrm{~h}$ (Figure 4). Since RANKL protein expression was induced by the exposure of $\mathrm{ARCaP}_{\mathrm{E}}$ cells to the growth factor milieu, we tested whether RANKL could mediate the growth factor-induced increase in cell migratory behaviors in an autocrine manner through interaction with RANK receptor on the cell surface. Co-treatment of $\mathrm{ARCaP}_{\mathrm{E}}$ cells with growth factors and a RANK decoy receptor, OPG $(50 \mathrm{ng} / \mathrm{ml})$, failed to show any suppressive effects on the migration of $\mathrm{ARCaP}_{\mathrm{E}}$ cells (Figure 4). In addition, OPG did not affect the migratory rate of $\mathrm{ARCaP}_{\mathrm{M}}$ (data not shown). Conversely, the threefold increase of $\mathrm{ARCaP}_{\mathrm{E}}$ migration stimulated by recombinant RANKL (200 ng/ml) was completely abolished by co-treatment of these cells with both recombinant RANKL and OPG (Figure 4). Together, these results suggest that RANKL was not directly responsible for the increase in cell migration induced by EGF and TGF $\beta 1$, but instead EGF and TGF $\beta 1$ may induce cell migration via a RANKL-independent pathway. Although EGF and TGF $\beta 1$ did increase invasion slightly in $\mathrm{ARCaP}_{\mathrm{E}}$ cells, the difference was not statistically significant. In addition, neither RANKL nor its inhibitor OPG was able to affect cell invasion (Figure 4). These results are consistent with the interpretation that EGF and TGF $\beta 1$ utilize distinct signaling pathways, independent 

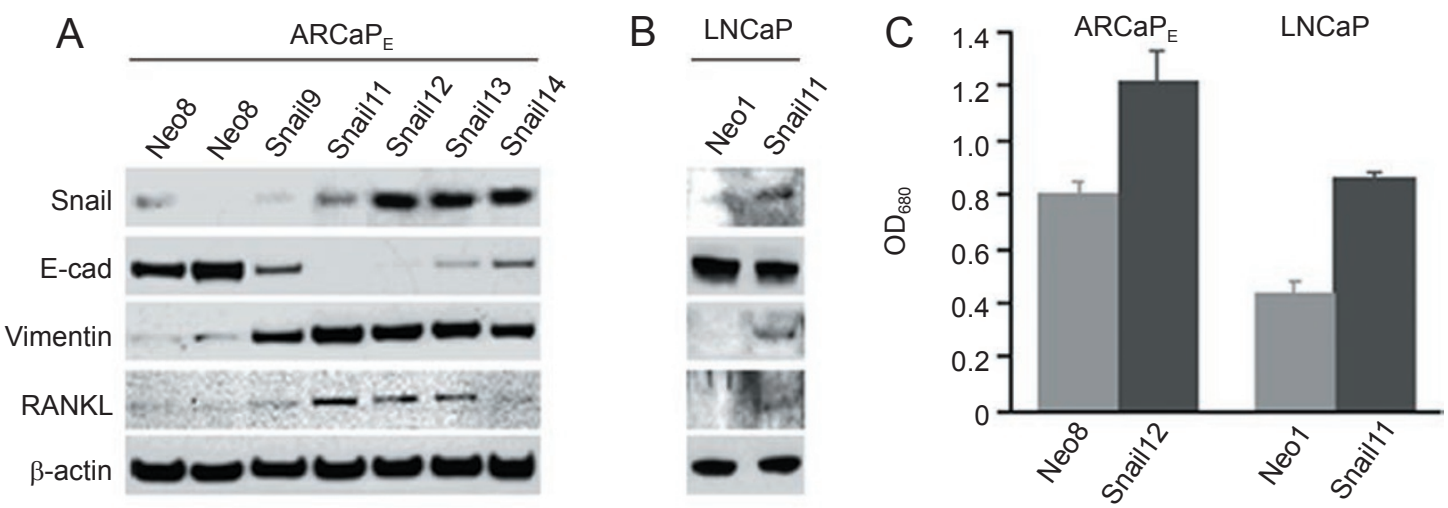

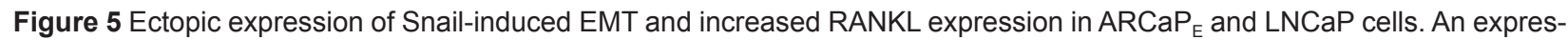
sion vector containing a constitutively active Snail CDNA was stably transfected into (A) ARCaP $\mathrm{E}_{\mathrm{E}}$ cells or (B) LNCaP cells, and EMT markers were analyzed by Western blot. Panels (A) and (B) are the representative blots of gene expression in selected Snail- and neo-transfected clones. (C) Cell migration was analyzed using a Boyden chamber coated on the underside with collagen. OD590 $\mathrm{nm}$ represents relative migration. Panel (C) represents the average \pm standard deviation from four separate experiments with 2-3 replicates per experiment.

of RANKL and its interaction with RANK, in the induction of cell migration and invasion of $\mathrm{ARCaP}_{\mathrm{E}}$ cells.

Snail is a common mediator of EMT in human LNCaP and ARCaP prostate cancer cell models: evidence of increased RANKL expression and cell migration

Because of the possible roles of Snail in EMT, we transfected $\mathrm{ARCaP}_{\mathrm{E}}$ and $\mathrm{LNCaP}$ cells with either Snail cDNA or empty Neo control vector. Stable clones were generated by neomycin selection and characterized. The Snail-transfected $\mathrm{ARCaP}_{\mathrm{E}}$ clones expressed higher levels of Snail than those in the Neo control on Western blot analysis (Figure 5A). In addition, the Snail-transfected clones had decreased E-cadherin and increased vimentin and RANKL expressions, consistent with EMT. The Snail-transfected LNCaP cells also underwent EMT with concomitant gene expression changes, with the exception that E-cadherin expression was not changed at the cellular level (Figure 5B). Instead, immunocytochemical analysis of the transfected clones suggested a re-organization of the E-cadherin proteins, shifted from cell junctions to a predominantly cytoplasmic localization (Supplementary information, Figure S1). Importantly, the Snail-induced EMT was accompanied by increased cell migration in both $\mathrm{ARCaP}_{\mathrm{E}}(30 \%)$ and $\mathrm{LNCaP}(50 \%)$ when representative Snail transfectants were compared to control Neo clones (Figure 5C).

Increased in vitro osteoclastogenesis in $A R C a P_{M}$ and ARCaP ${ }^{-}$-Snail cells

We next examined whether elevated RANKL expression by the $\mathrm{ARCaP}_{\mathrm{M}}$ or Snail-transfected $\mathrm{ARCaP}_{\mathrm{E}}$ cells was functional. An in vitro osteoclastogenesis assay was performed to quantify osteoclast maturation. Cancer cells co-cultured with mouse splenocytes for 14 days induced the pre-osteoclast progenitor cells to form mature multinucleated osteoclasts, which showed positive TRAP stain (Figure 6A and 6B). A two-fold increase in mature osteoclast numbers was noted in $\mathrm{ARCaP}_{\mathrm{M}}$ co-cultures, compared to $\mathrm{ARCaP}_{\mathrm{E}}$ co-cultures. Treatment of $\mathrm{ARCaP}_{\mathrm{M}}$ co-cultures with OPG abrogated the osteoclastogenesis and reduced the number of mature osteoclasts (Figure 6A and $6 \mathrm{~B})$. Similarly, $\mathrm{ARCaP}_{\mathrm{E}}$ cells overexpressing Snail (ARCaP-Snail12) led to increased TRAP staining with a drastic 40-fold increase in multi-nucleated osteoclasts, and this increase could be partially inhibited by OPG (Figure $6 \mathrm{C})$. These results suggest that the RANKL produced by $\mathrm{ARCaP}_{\mathrm{M}}$ and $\mathrm{ARCaP}_{\mathrm{E}}$-Snail cells is biologically functional, inducing osteoclastogenesis in vitro. Finally, to assess the regulation of RANKL expression by the Snail transcription factor, clones of the Snail-transfected $\mathrm{ARCaP}_{\mathrm{E}}$ cells were intracardiacally injected to SCID mice. The spontaneous bone tumors were dissected for TRAP staining for osteoclasts. There was an elevated number of TRAP-positive osteoclasts lining the bone surface (Figure 6D), indicative of increased RANKL activity in the Snail-transfected $\mathrm{ARCaP}_{\mathrm{E}}$ clones.

\section{Discussion}

The prevalence of prostate cancer and its propensity to skeletal metastases are well recognized [40]. Most men who die of prostate cancer have metastatic bone disease [41]. The present communication focused on determining the causal relationship between human prostate cancer 
A

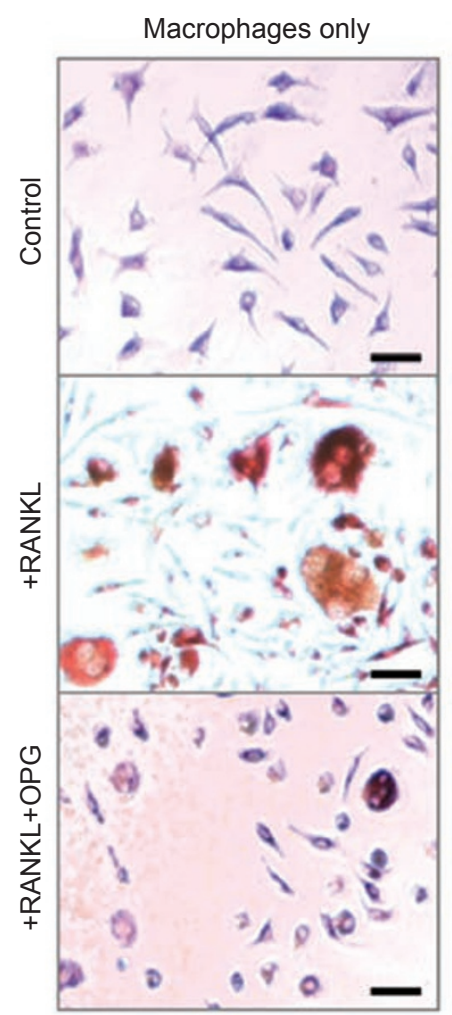

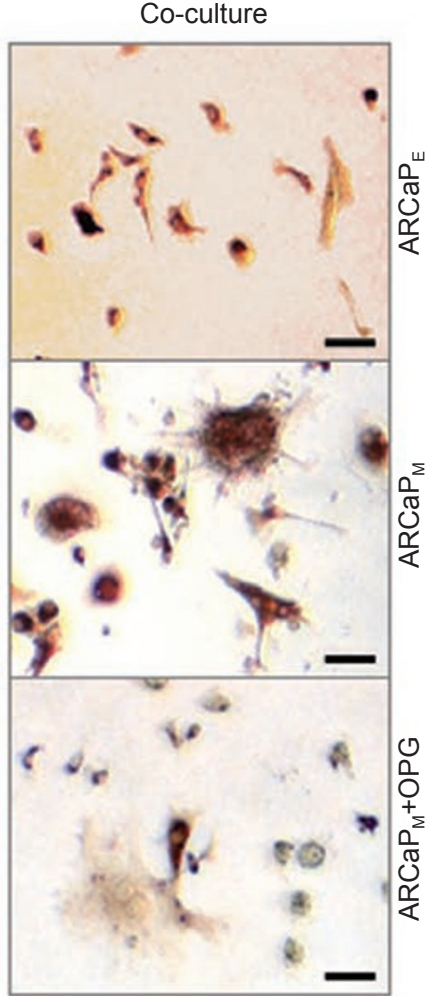
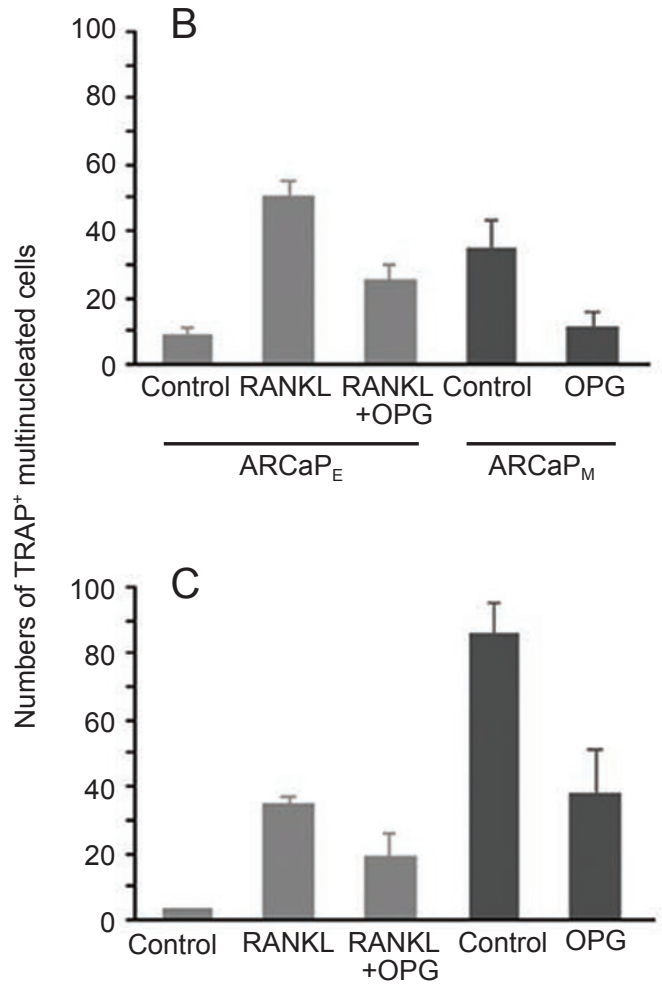

Macrophages
$\mathrm{ARCaP}_{\mathrm{E}} /$ Snail clone 12

$\mathrm{D}$

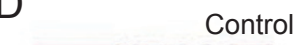

Control

$\mathrm{ARCaP}_{\mathrm{E}} / \mathrm{Neo8}$

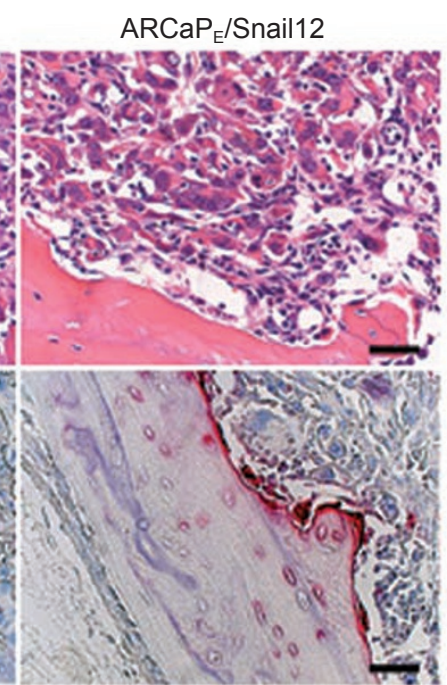

Figure 6 Increased osteoclastogenesis in vitro upon co-culturing mouse macrophage cells with ARCaP ${ }_{M}$ or ARCaP-Snail transfectants. (A) ARCaP ${ }_{M}$ cells that overexpress RANKL when co-cultured with mouse macrophage cells induced more TRAP staining as seen under light microscopy, as compared to $A R C a P_{E}$ co-cultures, which was effectively antagonized by OPG, suggesting that the RANKL overexpressed by $\mathrm{ARCaP}_{\mathrm{M}}$ cells is functional. Bar $=120 \mu \mathrm{m}$. (B) Multinucleated TRAP positive cells from $A R C a P_{E}$ or $A_{R C a P}$ co-cultures were counted under a light microscope. (C) Co-culture of ARCaP-Snail12 performed similarly revealed increased multinucleated TRAP-positive cells compared to the Neo control. The results represent triplicate results obtained from two independent experiments. (C) One of the Snail-transfected $A R C a P_{E}$ cell clones was intracardiacally injected to SCID mice and the spontaneous bone metastatic tumors were dissected for TRAP staining of osteoclasts. An elevated number of TRAP-positive osteoclasts lining the bone surface was observed, indicative of an increased RANKL activity in the Snail-transfected $\mathrm{ARCaP}_{\mathrm{E}}$ clones. Bar $=240 \mu \mathrm{m}$. 
bone metastasis and EMT using a newly established human prostate cancer ARCaP EMT model. Results of our study demonstrated that the host bone microenvironment, selected soluble growth factors, and the Snail transcription factor could provoke EMT in ARCaP human prostate cancer cells. Specifically, we identified the expression of functional RANKL as a novel EMT marker which may be responsible, in part, for increased bone turnover and subsequent prostate cancer cell growth and bone colonization.

EMT occurs during embryonic development, where the invasion front of migrating primordial epithelial cells undergoes morphologic and behavioral transition, starting to express mesenchymal phenotypes and biomarkers [1]. It has been widely reported that cancer cells similarly undergo EMT, leading to increased migratory, invasive, and metastatic potential [5-7]. Despite reports claiming that vimentin may be co-expressed in localized and disseminated prostate cancers with increased oncogenic signals [30, 42], there was little documentation of biologic and molecular associations between vimentin expression and the behaviors of human prostate cancer cells. In this study, we showed that vimentin expression was intimately associated with EMT in both the $\mathrm{ARCaP}$ and $\mathrm{LNCaP}$ prostate cancer cell lines, and we have identified classical as well as novel biomarkers associated with this transition.

We noted consistent morphologic and behavioral changes associated with EMT in the ARCaP model and this transition could predict the metastatic potential of prostate cancer cells to bone. We identified RANKL as a novel EMT-associated biomarker in both ARCaP and Snailtransfected LNCaP cells. Under physiologic conditions, RANKL, expressed by osteoblasts, stimulates osteoclast maturation and bone resorption through the surface RANK receptor-expressing osteoclasts $[43,44]$. Our data indicated that $\mathrm{ARCaP}_{\mathrm{M}}$ cells expressing mesenchymal phenotype and Snail-transfected LNCaP cells could mimic osteoblasts by expressing higher levels of RANKL, and the expression led to increased osteoclast maturation. These results suggest that EMT may be associated with bone-homing or increased bone turnover elicited by the invading prostate cancer cells.

The soluble factors TGF $\beta 1$ and EGF were also able to induce EMT in ARCaP cells by down-regulating E-cadherin, and up-regulating vimentin, Snail, and RANKL. TGF $\beta 1$ has been shown previously to increase Snail expression and osteoclastogenesis through regulation of RANKL protein, while EGF has so far only been shown to regulate Snail [45-48]. We propose that the regulation of bone turnover by TGF $\beta$ may be mediated, in part, through Snail-regulated RANKL expression, and we are currently testing this hypothesis. Recent findings indicated that RANKL is important for the migration and homing of melanoma cancer cells to bone [49]. It is possible that EMT may couple with prostate cancer bone homing through RANKL expression, its ability to increase bone turnover, and subsequent bone colonization.

It appears that up-regulation of RANKL is a common feature of EMT, whether it is induced by cellular interaction with the bone microenvironment, treatment with TGF $\beta 1$ and EGF, or by transfecting with the Snail transcription factor. To our knowledge this is the first report showing that the additive effects of TGF $\beta 1$ and EGF, and Snail transfection can increase RANKL expression. TGF $\beta 1$ has previously been shown to induce RANKL expression and subsequently stimulate osteoclast differentiation $[45,48]$. There are no reports of RANKL regulation by EGF alone or co-regulation by TGF $\beta 1$ plus EGF. Our results indicated that combined EGF and TGF $\beta 1$, but not these growth factors alone, elicited increased cell migration and that these effects could not be abrogated by OPG. In control experiments, however, pharmacologic doses of recombinant RANKL did lead to increased cell migration, and the effect could be blocked by OPG. These results are in agreement with a previous report that RANKL induced migration in breast and prostate cancer cells [49]. Because very high concentrations of RANKL were needed to promote prostate cancer cell migration, the RANKL level observed in AR$\mathrm{CaP}$ cells may be too low to elicit a cell migration effect. Instead, the level of RANKL in ARCaP may be sufficient for osteoclastogenesis, bone resorption, and turnover, and for supporting prostate cancer bone colonization.

The Snail transcription factor has been shown to induce EMT in breast, ovarian, and bladder cancers [13-16]. Its direct effect on prostate cancer cells, however, has not been extensively investigated. Down-regulation of prostasin gene in hormone-refractory prostate cancer has been shown to be mediated by the Snail homolog, Slug, through the repression of prostasin promoter [28]. In the TRAMP/ FVB mouse prostate cancer progression model, genistein was shown to inhibit cancer growth and progression in vivo by down-regulating Snail [50]. We demonstrated that overexpression of Snail in $\mathrm{ARCaP}_{\mathrm{E}}$ and $\mathrm{LNCaP}$ cells was able to drive EMT characterized by decreased E-cadherin expression, or relocalization of E-cadherin in $\mathrm{LNCaP}$ from the cytoplasmic membrane junction to the cytosol. This was accompanied by increased vimentin and RANKL protein expression, as well as increased cell migration. Furthermore, the Snail-induced RANKL in $\mathrm{ARCaP}_{\mathrm{E}}$ cells was functional and could increase osteoclastogenesis in vitro. This is the first documented report of Snail regulation of RANKL protein and osteoclast maturation and provides a crucial link between EMT and possible bone turnover. Snail has been reported to be important for chondrocyte differentiation and was highly expressed in hypertrophic 
chondrocytes of developing mouse limb [51]. There is no documentation of the role of Snail in bone, and further studies are going on to investigate the link between Snail regulation of RANKL, bone turnover, and prostate cancer bone metastasis.

Our results revealed that the factors that drive EMT can also regulate RANKL expression in human prostate cancer, and RANKL is a common mediator downstream from growth factors (TGF $\beta 1$ and EGF), bone microenvironment, and Snail activation. Several studies have shown the efficacy of targeting RANKL in myeloma and prostate cancer bone lesions. Recombinant OPG linked to an Fc portion of immunoglobulins (OPG-Fc), decoy RANK-Fc receptor, or humanized RANKL antibodies has been developed [5254]. On the other hand, our studies suggest that inhibitors of TGF $\beta 1$, EGF, or Snail signaling may not only prevent EMT, but also retard the RANK-RANKL signaling. These inhibitors should be evaluated for their efficacy to prevent EMT, metastasis, and subsequent colonization of prostate cancer cells in bone.

In summary, we showed that EMT in human prostate cancer could be induced and maintained through interaction with the bone microenvironment, by treatment with growth factors EGF and TGF $\beta 1$, and following Snail overexpression. The morphologic and behavioral switch for $\mathrm{ARCaP}_{\mathrm{E}}$ cells to undergo EMT was accompanied by decreased E-cadherin, and increased $\mathrm{N}$-cadherin, vimentin, and RANKL expression. The functional RANKL could enhance bone resorption and bone turnover, which could facilitate subsequent prostate cancer bone metastasis. Since increased RANKL expression was detected in both LNCaP and ARCaP human prostate cancer EMT models, targeting RANKL-RANK plus specific growth factor signaling interrupting EMT may offer advantages for the treatment of human prostate cancer bone metastasis.

\section{Materials and Methods}

\section{Reagents and antibodies}

T-medium was purchased from Invitrogen (Carlsbad, CA). Penicillin-streptomycin was from BioWhittaker (Walkersville, MD). RPMI 1640 medium was from Life Technologies, Inc. (Rockville, MD). The protease inhibitor cocktail was from Roche Molecular Biochemicals (Indianapolis, IN). Mouse monoclonal anti-human E-cadherin and $\mathrm{N}$-cadherin antibodies were from BD Transduction Laboratories (Lexington, KY). Goat polyclonal anti-human RANKL and mouse monoclonal anti-human vimentin antibodies were from Santa Cruz Biotechnology (Santa Cruz, CA). Recombinant human TGF $\beta 1$, recombinant mouse RANKL, recombinant mouse M-CSF, and recombinant human OPG were from R\&D Systems, Inc. (Minneapolis, MN). Fetal bovine serum (FBS), recombinant human EGF, G418, anti-flag M2 monoclonal antibody, and mouse monoclonal anti-human $\beta$-actin antibody were from Sigma-Aldrich, Inc. (St Louis, MO). Rat monoclonal anti-human Snail antibody and HRP- conjugated goat anti-rat antibody were from Cell Signaling Technology, Inc. (Danvers, MA). HRP-conjugated sheep anti-mouse antibody and the Enhanced chemiluminescence (ECL) detection reagent were purchased from Amersham Biosciences (Buckingham, England). HRP-conjugated rabbit anti-goat antibody was from Zymed Laboratories Inc. (San Francisco, CA). Matrigel and rat tail type-1 collagen were from BD Biosciences. Charcoal/dextran-treated FBS (DCC-FBS) was from Hyclone (South Logan, UT). The Snail cDNA construct was kindly provided by Dr Mien-Chie Hung, University of Texas (Houston, TX).

\section{Cells and culture conditions}

The human prostate cancer $\mathrm{LNCaP}$ cell line was obtained from ATCC (Manassas, VA). ARCaP cells were established from the ascites fluid of a patient with prostate cancer bone metastasis [55]. $\mathrm{ARCaP}_{\mathrm{E}}$ and $\mathrm{ARCaP}_{\mathrm{M}}$ are sublines of the $\mathrm{ARCaP}$, generated in our laboratory by limited dilution cloning [30]. All the cells were grown in T-medium supplemented with $5 \%$ fetal bovine serum $(10 \%$ for ARCaP sublines) and $1 \times$ penicillin-streptomycin, at $37^{\circ} \mathrm{C}$ with $5 \%$ $\mathrm{CO}_{2}$ in a humidified incubator.

\section{Transfection assay}

Stable transfection of Snail cDNA was performed in $\mathrm{ARCaP}_{\mathrm{E}}$ and LNCaP cells utilizing Lipofectamine 2000 (Invitrogen). A constitutively active Snail construct (6SA) was previously utilized to induce EMT in MCF7 breast cancer cells [33]. Briefly, $1.6 \mu \mathrm{g}$ Snail cDNA or empty vector (Neo) was transfected into cells cultured in 12-well dishes at $90 \%$ confluence as per the manufacturer's instructions. Stable clones were selected using $800 \mu \mathrm{g} / \mathrm{ml} \mathrm{G} 418$, isolated, and maintained in $400 \mu \mathrm{g} / \mathrm{ml} \mathrm{G418}$. Snail expression was verified in the clones by Western blot analysis.

\section{Animal experiments}

All animal procedures were approved and performed in accordance with institutional guidelines, and all mice were purchased from National Cancer Institute (Frederick, MD). $\mathrm{ARCaP}_{\mathrm{E}}$ cells were injected by intracardiac route $\left(5 \times 10^{5}\right.$ cells $\left./ 50 \mu 1 \mathrm{PBS}\right)$ into five- to seven-week-old male SCID mice $(\mathrm{n}=8)$ using a $28 \mathrm{G} 1 / 2$ needle. Prior to injection, mice were anesthetized and placed in a supine position and the needle inserted $5 \mathrm{~mm}$ above the middle of the left side of sternum. The appearance of fresh arterial blood in the syringe signaled successful penetration into the left ventricle, and cells were subsequently infused slowly and directly into the left ventricle of the mouse for systemic circulation. Tumor formation in bone was monitored closely by biweekly X-ray radiography. The time taken for the tumor to be visualized by X-ray was termed the latency period, and metastasis was confirmed by radiography and histomorphology of the tumor specimens.

Bone metastasis tumor was dissected to clone cancer cells from the tumor. Cells were derived from bone metastatic tumor tissue by culturing tumor dices in vitro. Cloned cells represented the bone metastatic variant of the original cancer cell line. The variant cells were used in another round of bone tumor formation following intracardiac injection into SCID mice.

\section{Reverse transcription-polymerase chain reaction (RT-PCR)}

Total RNA was isolated from cells using RNA-Bee as per the manufacturer's instructions (Tel-Test, Inc., Friendswood, TX). The RNA $(2 \mu \mathrm{g})$ was reverse transcribed with oligo-dT using MMLV- 
reverse transcriptase (Invitrogen, Carlsbad, CA), to generate cDNA. PCR analyses were subsequently performed with $2 \mu \mathrm{l}$ of the cDNA reaction utilizing the primers and conditions as follows. E-cadherin primers used were: $5^{\prime}$-TCC ATT TCT TGG TCT ACG CC-3' and 5'-CAC CTT CAG CCAACC TGT TT-3'; N-cadherin, 5'-GTG CCA TTA GCC AAG GGA ATT CAG C- $3^{\prime}$ and $5^{\prime}$-GCG TTC CTG TTC CAC TCA TAG GAG G-3'. The PCR conditions for E-cadherin and $\mathrm{N}$-cadherin were $95^{\circ} \mathrm{C}, 5 \mathrm{~min}, 35$ cycles of $95^{\circ} \mathrm{C}, 30 \mathrm{~s} ; 60^{\circ} \mathrm{C}$, $30 \mathrm{~s} ; 72^{\circ} \mathrm{C}, 60 \mathrm{~s}$, and $72{ }^{\circ} \mathrm{C}, 8 \mathrm{~min}$ final extension. Vimentin primers used were: $5^{\prime}$-TGG CAC GTC TTG ACC TTG AA-3' and 5'-GGT CAT CGT GAT GCT GAG AA-3'; RANKL: 5'-GCT TGA AGC TCA GCC TTT TGC TCA T- $3^{\prime}$ and $5^{\prime}$-GGG GTT GGA GAC CTC GAT GCT GAT T-3'. The PCR conditions for vimentin were $94{ }^{\circ} \mathrm{C}, 2$ min, 29 cycles of $94{ }^{\circ} \mathrm{C}, 30 \mathrm{~s} ; 55^{\circ} \mathrm{C}, 30 \mathrm{~s} ; 72{ }^{\circ} \mathrm{C}, 2 \mathrm{~min}$, and $72 \mathrm{C}, 7$ min final extension, while those for RANKL were $94{ }^{\circ} \mathrm{C}, 2 \mathrm{~min}$, 36 cycles of $94{ }^{\circ} \mathrm{C}, 15 \mathrm{~s} ; 55^{\circ} \mathrm{C}, 30 \mathrm{~s} ; 72{ }^{\circ} \mathrm{C}, 60 \mathrm{~s}$, and $72{ }^{\circ} \mathrm{C}, 5$ min final extension.

\section{Western blot analysis}

Confluent cells were lysed in a modified RIPA buffer $(50 \mathrm{mM}$ Tris, pH 8.0, $150 \mathrm{mM} \mathrm{NaCl}, 0.02 \% \mathrm{NaN}_{3}, 0.1 \%$ SDS, $1 \% \mathrm{NP}-40$, $0.5 \%$ sodium deoxycholate) containing $1.5 \times$ protease inhibitor cocktail, $1 \mathrm{mM}$ phenylmethylsulfonyl fluoride, and $1 \mathrm{mM}$ sodium orthovanadate. The cell lysates were centrifuged, and supernatants collected and quantified using a micro BCA assay. In all, 25-30 $\mu \mathrm{g}$ of cell lysate was resolved on a $4-12 \%$ SDS-PAGE, followed by transblotting onto nitrocellulose membrane (Schleicher \& Schuell, Keene, NH). The membranes were blocked in TBSTB (TBS with $0.05 \%$ Tween-20, $0.05 \%$ BSA) containing $5 \%$ fat-free milk, and subsequently incubated with diluted antibody in blocking buffer. After washing, the membranes were incubated in peroxidase-conjugated secondary antibodies, washed, and visualized using ECL reagent. The membranes were stripped using stripping buffer (Pierce Biotechnology, Inc., Rockford, IL) prior to re-probing with a different antibody. For growth factor treatments, $70 \%$ confluent cells were serum-starved in phenol-free serum-free RPMI containing penicillin/streptomycin for $24 \mathrm{~h}$ prior to treatment with $4 \mathrm{ng} / \mathrm{ml} \mathrm{TGF} \beta 1$, or $50 \mathrm{ng} / \mathrm{ml} \mathrm{EGF}$, or a combination of both for various time periods in the RPMI1640 supplemented with 5\% DCC-FBS. Cell lysates were subsequently prepared.

\section{Invasion and migration assays}

Cells treated with $4 \mathrm{ng} / \mathrm{ml}$ TGF $\beta 1$ plus $50 \mathrm{ng} / \mathrm{ml} \mathrm{EGF,} 200 \mathrm{ng} / \mathrm{ml}$ RANKL, or $50 \mathrm{ng} / \mathrm{ml} \mathrm{OPG}$ for 3 days were harvested and $5 \times 10^{4}$ cells plated in the upper chamber of a 24-well costar transwell Boyden chamber (Becton Dickinson, Franklin Lakes, NJ) that had been previously coated on the inside of the well with matrigel:media (1:4) for invasion, or on the underside of each well with $2.5 \mu \mathrm{g} / \mathrm{cm}^{2}$ collagen I for migration assays. The haptotactic invasion and migration assays were performed in RPMI 1640 media supplemented with 5\% DCC in the case of ARCaP cells, while for the less migratory LNCaP cells a chemotactic migration assay was performed by adding $0.1 \%$ FBS to the bottom wells. The cells that had invaded/migrated to the underside of the membrane and the bottom chamber were fixed with formaldehyde after $48 \mathrm{~h}$ (for migration) or $72 \mathrm{~h}$ (for invasion), and stained with $0.5 \%$ crystal violet. For invasion assays, cells stained on the underside of the membrane and in the bottom chamber were solubilized with extraction buffer (Chemicon International, Inc.,
Temecula, CA), and OD590 nm was subsequently read to get the relative invasion. For migration assays cells on the underside of the membrane were scraped, and stained cells that had migrated to the bottom chamber were manually counted or solubilized and OD590 $\mathrm{nm}$ was read to obtain the relative migration.

\section{Immunohistochemical analysis}

$2 \times 10^{4}$ cells were plated onto chamber slides in T-media containing $10 \%$ FBS. After overnight culture, the cells were placed in phenol-free serum-free RPMI 1640 medium containing penicillin/ streptomycin for $24 \mathrm{~h}$ prior to treatment with $4 \mathrm{ng} / \mathrm{ml} \mathrm{TGF} \beta 1$ and $50 \mathrm{ng} / \mathrm{ml}$ EGF for various time periods up to $72 \mathrm{~h}$ in RPMI media supplemented with 5\% DCC-FBS. The cells were fixed with ice-cold methanol/acetone $(1: 1)$, followed by immunoperoxidase staining utilizing the DAKO Autostainer Plus System (DAKO, Capinteria, CA). All common reagents for staining were from DAKO. Briefly, the slides were blocked with dual endogenous enzyme block (DEEB) for $10 \mathrm{~min}$, incubated for $1 \mathrm{~h}$ with primary antibody, E-cadherin (1:1 000), vimentin (1:50), N-cadherin (1:500), RANKL (1:500), or control UNC antibodies (DAKO). A thorough rinse in Tris-buffered saline with $0.05 \%$ Tween (TBST) was followed by $30 \mathrm{~min}$ incubation with Envision + Labelled Polymer-HRP or 15 min incubation with Biotinylated Link Universal and 15 min Streptavidin-HRP. The staining signal was detected by incubating with peroxidase substrate buffer with chromogen, diaminobenzidine (DAB), followed by hematoxylin counterstain. Following cover-slipping, images were acquired using a laser-scan confocal microscope 410 (Carl Zeiss, Minneapolis, MN).

\section{In vitro osteoclastogenesis assay}

Osteoclastogenesis assay was performed as described previously with minor modifications [56]. Briefly, $1 \times 10^{3}$ cancer cells were seeded together with $2 \times 10^{5}$ pre-osteoclastic macrophage cells harvested from adult mouse spleen by disaggregation through a wire sieve. The co-cultures were performed in a 48-well plate containing $500 \mu \mathrm{l}$ of $\alpha$-MEM media supplemented with $10 \% \mathrm{FBS}$, and $1 \mathrm{ng} / \mathrm{ml}$ mouse recombinant M-CSF. As a positive control, $100 \mathrm{ng} / \mathrm{ml}$ mouse recombinant RANKL was added to $2 \times 10^{5}$ pre-osteoclastic cells. 50 $\mathrm{ng} / \mathrm{ml}$ recombinant OPG was added to certain wells to block RANKLmediated osteoclastogenesis. The cells were fed twice a week by replacement of half the media with fresh media containing M-CSF (and RANKL for the positive control). After 14 days, the cells were fixed and analyzed by TRAP staining (Sigma-Aldrich, Inc., St Louis), and the $\mathrm{TRAP}^{+}$multinucleated cells in the entire well were counted as mature osteoclasts. Note that TRAP stain is associated solely with macrophage cells; ARCaP cells when cultured individually or in co-culture with macrophage cells had a distinct morphology and individually were devoid of TRAP stain (data not shown).

\section{Acknowledgments}

We thank Dr Neale Weitzmann (Department of Medicine, Emory University School of Medicine) for helpful discussion and support, and Mr Gary Mawyer (Department of Urology, the University of Virginia) for editing. We acknowledge the following grant supports: CA 082739 (HEZ); CA 119338, CA 098912, CA 132388, CA 108468 and PC060866 (LWKC). 


\section{References}

1 Hay ED. An overview of epithelio-mesenchymal transformation. Acta Anat (Basel) 1995; 154:8-20.

2 Bellovin DI, Bates RC, Muzikansky A, Rimm DL, Mercurio AM. Altered localization of p120 catenin during epithelial to mesenchymal transition of colon carcinoma is prognostic for aggressive disease. Cancer Res 2005; 65:10938-10945.

3 Rosano L, Spinella F, Di Castro V, et al. Endothelin-1 promotes epithelial-to-mesenchymal transition in human ovarian cancer cells. Cancer Res 2005; 65:11649-11657.

4 Yang AD, Camp ER, Fan F, et al. Vascular endothelial growth factor receptor-1 activation mediates epithelial to mesenchymal transition in human pancreatic carcinoma cells. Cancer Res 2006; 66:46-51.

5 Boyer B, Valles AM, Edme N. Induction and regulation of epithelial-mesenchymal transitions. Biochem Pharmacol 2000; 60:1091-1099.

6 Petersen OW, Nielsen HL, Gudjonsson T, et al. Epithelial to mesenchymal transition in human breast cancer can provide a nonmalignant stroma. Am J Pathol 2003; 162:391-402.

7 Thiery JP. Epithelial-mesenchymal transitions in tumour progression. Nat Rev Cancer 2002; 2:442-454.

8 Savagner P. Leaving the neighborhood: molecular mechanisms involved during epithelial-mesenchymal transition. Bioessays 2001; 23:912-923.

9 Savagner P, Boyer B, Valles AM, Jouanneau J, Thiery JP. Modulations of the epithelial phenotype during embryogenesis and cancer progression. Cancer Treat Res 1994; 71:229-249.

10 Janda E, Lehmann K, Killisch I, Jechlinger M, Herzig M, Downward J, et al. Ras and TGF[beta] cooperatively regulate epithelial cell plasticity and metastasis: dissection of Ras signaling pathways. J Cell Biol 2002; 156:299-313.

11 Morali OG, Delmas V, Moore R, Jeanney C, Thiery JP, Larue L. IGF-II induces rapid beta-catenin relocation to the nucleus during epithelium to mesenchyme transition. Oncogene 2001; 20:4942-4950.

12 Hauschka PV, Mavrakos AE, Iafrati MD, Doleman SE, Klagsbrun M. Growth factors in bone matrix. Isolation of multiple types by affinity chromatography on heparin-Sepharose. $\mathrm{J} \mathrm{Biol} \mathrm{Chem}$ 1986; 261:12665-12674.

13 Kurrey NK,Amit K, Bapat SA. Snail and Slug are major determinants of ovarian cancer invasiveness at the transcription level. Gynecol Oncol 2005; 97:155-165.

14 Moody SE, Perez D, Pan TC, et al. The transcriptional repressor Snail promotes mammary tumor recurrence. Cancer Cell 2005; 8:197-209.

15 Yokoyama K, Kamata N, Fujimoto R, et al. Increased invasion and matrix metalloproteinase-2 expression by Snail-induced mesenchymal transition in squamous cell carcinomas. Int J Oncol 2003; 22:891-898.

16 Taki M, Verschueren K, Yokoyama K, Nagayama M, Kamata $\mathrm{N}$. Involvement of Ets-1 transcription factor in inducing matrix metalloproteinase-2 expression by epithelial-mesenchymal transition in human squamous carcinoma cells. Int J Oncol 2006; 28:487-496.

17 Untergasser G, Gander R, Rumpold H, Heinrich E, Plas E, Berger P. TGF-beta cytokines increase senescence-associated beta-galactosidase activity in human prostate basal cells by supporting differentiation processes, but not cellular senescence. Exp Gerontol 2003; 38:1179-1188.

18 Zhau HY, Zhou J, Symmans WF, et al. Transfected neu oncogene induces human prostate cancer metastasis. Prostate 1996; 28:7383.

19 Veveris-Lowe TL, Lawrence MG, Collard RL, et al. Kallikrein 4 (hK4) and prostate-specific antigen (PSA) are associated with the loss of E-cadherin and an epithelial-mesenchymal transition (EMT)-like effect in prostate cancer cells. Endocr Relat Cancer 2005; 12:631-643.

20 Kong YY, Yoshida H, Sarosi I, et al. OPGL is a key regulator of osteoclastogenesis, lymphocyte development and lymph-node organogenesis. Nature 1999; 397:315-323.

21 Yasuda H, Shima N, Nakagawa N, et al. Osteoclast differentiation factor is a ligand for osteoprotegerin/osteoclastogenesis-inhibitory factor and is identical to TRANCE/RANKL. Proc Natl Acad Sci USA 1998; 95:3597-3602.

22 Standal T, Seidel C, Hjertner O, et al. Osteoprotegerin is bound, internalized, and degraded by multiple myeloma cells. Blood 2002; 100:3002-3007.

23 Mundy GR. Metastasis to bone: causes, consequences and therapeutic opportunities. Nat Rev Cancer 2002; 2:584-593.

24 Roudier MP, Corey E, True LD, Hiagno CS, Ott SM, Vessell RL. Histological, immunophenotypic and histomorphometric characterization of prostate cancer bone metastases. Cancer Treat Res 2004; 118:311-339.

25 Seibel MJ. Clinical use of markers of bone turnover in metastatic bone disease. Nat Clin Pract Oncol 2005; 2:504-517.

26 Mundy GR. Mechanisms of bone metastasis. Cancer 1997; 80(8 Suppl):1546-1556.

27 Brown JM, Corey E, Lee ZD, et al. Osteoprotegerin and rank ligand expression in prostate cancer. Urology 2001; 57:611-616.

28 Chen G, Sircar K, Aprikian A, Potti A, Goltzman D, Rabbani SA. Expression of RANKL/RANK/OPG in primary and metastatic human prostate cancer as markers of disease stage and functional regulation. Cancer 2006; 107:289-298.

29 Brown JM, Zhang J, Keller ET. Opg, RANK1, and RANK in cancer metastasis: expression and regulation. Cancer Treat Res 2004; 118:149-172.

$30 \mathrm{Xu}$ J, Wang RX, Xie ZH, et al. Prostate cancer metastasis: role of the host microenvironment in promoting epithelial to mesenchymal transition and increased bone and adrenal gland metastasis. Prostate 2006; 66:1664-1673.

31 Barrallo-Gimeno A, Nieto MA. The Snail genes as inducers of cell movement and survival: implications in development and cancer. Development 2005; 132:3151-3161.

32 Hemavathy K, Ashraf SI, Ip YT. Snail/slug family of repressors: slowly going into the fast lane of development and cancer. Gene 2000; 257:1-12.

33 Zhou BP, Deng J, Xia W, et al. Dual regulation of Snail by GSK-3beta-mediated phosphorylation in control of epithelialmesenchymal transition. Nat Cell Biol 2004; 6:931-940.

34 Martin TJ. Paracrine regulation of osteoclast formation and activity: milestones in discovery. J Musculoskelet Neuronal Interact 2004; 4:243-253.

35 Schoppet M, Preissner KT, Hofbauer LC. RANK ligand and osteoprotegerin: paracrine regulators of bone metabolism and vascular function. Arterioscler Thromb Vasc Biol 2002; 22:549553. 
36 Bhowmick NA, Ghiassi M, Bakin A, et al. Transforming growth factor-beta1 mediates epithelial to mesenchymal transdifferentiation through a RhoA-dependent mechanism. Mol Biol Cell 2001; 12:27-36.

37 Cui W, Fowlis DJ, Bryson S, et al. TGFbeta1 inhibits the formation of benign skin tumors, but enhances progression to invasive spindle carcinomas in transgenic mice. Cell 1996; 86:531-542.

38 Oft M, Peli J, Rudaz C, Schwarz H, Beug H, Reichmann E. TGF-beta1 and Ha-Ras collaborate in modulating the phenotypic plasticity and invasiveness of epithelial tumor cells. Genes Dev 1996; 10:2462-2477.

39 Zhau HE, Odero-Marah V, Lue HW, et al. Epithelial to mesenchymal transition (EMT) in human prostate cancer: lessons learned from ARCaP model. Clin Exp Metastasis 2008 Jun 6. doi: 10.1007/s10585-008-9183-1

40 Boring CC, Squires TS, Tong T, Montgomery S. Cancer statistics, 1994. CA Cancer J Clin 1994; 44:7-26.

$41 \mathrm{Tu}$ SM, Lin SH. Clinical aspects of bone metastases in prostate cancer. Cancer Treat Res 2004; 118:23-46.

42 Lang SH, Hyde C, Reid IN, et al. Enhanced expression of vimentin in motile prostate cell lines and in poorly differentiated and metastatic prostate carcinoma. Prostate 2002; 52:253-263.

43 Aubin JE, Bonnelye E. Osteoprotegerin and its ligand: a new paradigm for regulation of osteoclastogenesis and bone resorption. Osteoporos Int 2000; 11:905-913.

44 Wong BR, Josien R, Lee SY, et al. TRANCE (tumor necrosis factor [TNF]-related activation-induced cytokine), a new TNF family member predominantly expressed in T cells, is a dendritic cell-specific survival factor. J Exp Med 1997; 186:2075-2080.

45 Ishida A, Fujita N, Kitazawa R, Tsuruo T. Transforming growth factor-beta induces expression of receptor activator of NF-kappa B ligand in vascular endothelial cells derived from bone. $J$ Biol Chem 2002; 277:26217-26224.

46 Peinado H, Olmeda D, Cano A. Snail, Zeb and bHLH factors in tumour progression: an alliance against the epithelial phenotype? Nat Rev Cancer 2007; 7:415-428.
47 Peinado H, Quintanilla M, Cano A. Transforming growth factor beta-1 induces snail transcription factor in epithelial cell lines: mechanisms for epithelial mesenchymal transitions. J Biol Chem 2003; 278:21113-21123.

48 Zhang J, Lu Y, Dai J, et al. In vivo real-time imaging of TGFbeta-induced transcriptional activation of the RANK ligand gene promoter in intraosseous prostate cancer. Prostate 2004; 59:360-369.

49 Jones DH, Nakashima T, Sanchez OH, et al. Regulation of cancer cell migration and bone metastasis by RANKL. Nature 2006; 440:692-696.

50 El Touny LH, Banerjee PP. Akt GSK-3 pathway as a target in genistein-induced inhibition of TRAMP prostate cancer progression toward a poorly differentiated phenotype. Carcinogenesis 2007; 28:1710-1717.

51 Seki K, Fujimori T, Savagner P, et al. Mouse Snail family transcription repressors regulate chondrocyte, extracellular matrix, type II collagen, and aggrecan. J Biol Chem 2003; 278:4186241870.

52 Body JJ, Facon T, Coleman RE, et al. A study of the biological receptor activator of nuclear factor-kappaB ligand inhibitor, denosumab, in patients with multiple myeloma or bone metastases from breast cancer. Clin Cancer Res 2006; 12:1221-1228.

53 Croucher PI, Shipman CM, Van Camp B, Vanderkerken K. Bisphosphonates and osteoprotegerin as inhibitors of myeloma bone disease. Cancer 2003; 97(Suppl):818-824

54 Zhang J, Dai J, Yao Z, Lu Y, Dougall W, Keller ET. Soluble receptor activator of nuclear factor kappaB Fc diminishes prostate cancer progression in bone. Cancer Res 2003; 63:7883-7890.

55 Zhau HY, Chang SM, Chen BQ, et al. Androgen-repressed phenotype in human prostate cancer. Proc Natl Acad Sci USA 1996; 93:15152-15157.

56 Takahashi N, Yamana H, Yoshiki S, et al. Osteoclast-like cell formation and its regulation by osteotropic hormones in mouse bone marrow cultures. Endocrinology 1988; 122:1373-1382.

(Supplementary Information is linked to the online version of the paper on the Cell Research website) 